\title{
APONTAMENTOS SOBRE A PROVINHA BRASIL NAS ESCOLAS MUNICIPAIS \\ DE IRATI-PR
}

\section{NOTES ON THE PROVINHA BRASIL AT THE MUNICIPAL SCHOOLS OF IRATI- PR}

\author{
Ângela Cleci Dzula Kovalchuk ${ }^{1}$ \\ Michelle Fernandes Lima
}

\section{Resumo:}

O presente artigo é resultado do Projeto de Iniciação Científica realizado na Universidade Estadual do Centro Oeste (IRATI-PR), que teve por objetivo o estudo sobre a Provinha Brasil e sua efetivação nas escolas municipais de Irati-Paraná. Para a realização da investigação utilizamos dados qualitativos e quantitativos, estruturamos este estudo em dois momentos: primeiramente, apresentamos o panorama geral da implantação da Provinha Brasil e do material utilizado para a aplicação desse tipo de avaliação e na seqüência analisamos a Provinha Brasil no contexto do município de Irati por meio de dados quantitativos; gráficos disponibilizados pela Secretaria Municipal de Educação (SME) e de dados qualitativos via entrevista concedida por uma das coordenadoras da SME.

Palavras-chave: Políticas Educacionais, Avaliação Nacional, Provinha Brasil.

\begin{abstract}
:
The present article is result of the Scientific Initiation Project performed at the Universidade Estadual do Centro Oeste (IRATI-PR), which had as objective the study on the Provinha Brasil and its effectuation in the municipal schools of Irati-Paraná. For the realization of the investigation we utilize qualitative and quantitative data, this study was structured in two moments: first of all, we presented the general panorama of the implantation of the Provinha Brasil and of the material utilized for the application of this kind of evaluation and further the Provinha Brasil is analyzed in the context of the city of Irati by means of quantitative data; graphics provided by the Secretaria Municipal de Educação (SME) and qualitative data via interview granted by one of the SME's coordinators.
\end{abstract}

Key Words: Educacional Politics, National Evaluation, Provinha Brasil.

\footnotetext{
${ }^{1}$ Pedagoga pela Universidade Estadual do Centro Oeste (Campus-Irati), angelaclechuk@ yahoo.com.br
} 


\section{Introdução}

As políticas educacionais a partir da década de 1990 foram delineadas sob a base neoliberal. Ideário disseminado na gestão Fernando Affonso Collor de Mello (1990-1992), e defendido pelos seus sucessores, principalmente no governo Fernando Henrique Cardoso (1995-1998; 1999-2002). O Neoliberalismo é uma ideologia que nasceu após a Segunda Guerra Mundial (1939-1945), sob a base filosófica da Escola Austríaca, fundada por Von Mises (1881-1973). Chegou ao poder em 1970, na Inglaterra, com a eleição de Margaret Thatcher e com Ronald Reagan nos Estados Unidos, visando consolidar-se como ideologia hegemônica no mundo. No Brasil esse ideário foi difundido a partir da década de 1990. Essa doutrina reforça a proposta do Estado mínimo, sem intervenção na saúde, na educação, na previdência social. Sua ação se restringe à segurança, justiça e à defesa nacional.

O pensamento neoliberal repercutiu de forma acentuada nas políticas educacionais brasileiras, especialmente na gestão de Fernando Henrique Cardoso (FHC), a qual pode ser caracterizada pela privatização do público, pela descentralização do ensino e práticas de controle. As políticas públicas neoliberais ganharam força, no que concerne à educação na Conferência Internacional de Educação para Todos, em Jomtien, na Tailândia, no ano de 1990. Essa Conferência teve como um dos principais organizadores o Banco Mundial, organismo internacional representante do sistema capitalista, que propõe uma gestão educacional na perspectiva da mercantilização. A ênfase da referida Conferência consistia na educação elementar de todas as pessoas, por isso, "Educação para Todos", para atender seu objetivo principal: a erradicação da pobreza via educação, por meio da preparação das pessoas para o mercado de trabalho.

Neste contexto, implantaram-se no Brasil as políticas de avaliação em larga escala para a educação básica, divulgadas pelo Ministério da Educação e Cultura (MEC), como uma prática que possibilita uma percepção mais ampla da realidade que contribui para diagnosticar a situação da educação brasileira. Esses apontamentos nos remetem ao objeto central da investigação que consiste na compreensão da influência neoliberal na educação brasileira,

\footnotetext{
${ }^{2}$ Professora do Curso de Pedagogia da Universidade Estadual do Centro Oeste (Campus-Irati PR). Doutora pelo Programa de Pós Graduação em Educação na linha de Políticas e Gestão da Universidade Federal do Paraná: mfernandeslima@yahoo.com.br.
} 
especialmente no que se refere à política de avaliação da educação básica, priorizando a análise da "Provinha Brasil".

Neste artigo priorizamos a análise da "Provinha Brasil", ilustrando a realidade dessa avaliação no contexto brasileiro e no município de Irati-Paraná, por meio de dados qualitativos e quantitativos a respeito da efetivação da avaliação nas escolas municipais.

Estruturamos este estudo em três partes: primeiramente, apresentamos o panorama geral da implantação da Provinha Brasil e do material utilizado para a aplicação desse tipo de avaliação, na seqüência analisamos a Provinha Brasil no contexto do município de Irati por meio de dados quantitativos; gráficos disponibilizados pela Secretaria Municipal de Educação de Irati (SME) e de dados qualitativos via entrevista concedida por uma das coordenadoras da SME, e finalizamos com algumas considerações sobre as seguintes categorias de análise: Centralização/Descentralização; Gestão Democrática; e Autonomia. Princípios defendidos e propagados a partir da Constituição Federal de 1988, tomando força no delineamento das políticas educacionais brasileiras sob a égide neoliberal.

\section{CONHECENDO A PROVINHA BRASIL}

A partir da instauração das políticas neoliberais no Brasil, na década de 1990, as políticas educacionais em nosso país foram desenhadas conforme o modelo de gestão do mercado, um dos exemplos mais acentuado são as avaliações nacionais em larga escala. A avaliação em larga escala como política pública, tal como hoje concebemos, foi delineada no Brasil, no início da década de 1980, época em que o Ministério da Educação e Cultura (MEC), começou a desenvolver estudos referentes à Avaliação Educacional, implantando em 1990, o Sistema de Avaliação da Educação Básica.

Segundo Gomes Neto e Rosenberg (1995), neste período, se vivenciava no país, um processo gradual de redemocratização, o que gerava um clima tanto de busca da universalização e qualificação da educação, quanto de percepção da necessidade de se construir instrumentos para a Avaliação em Larga Escala. Na década de 1990, deu-se a grande guinada de rumos que provocou mudanças profundas no cerne da educação brasileira, o Estado se torna no campo educacional, o regulador e avaliador das políticas e projetos implantados em todos os níveis e modalidades de ensino, com ênfase na educação básica. Especialmente, após a promulgação da Lei de Diretrizes e Bases da Educação Nacional (Lei 9394/96). Segundo a LDB, no Art. 9, Inciso VI, entre as incumbências da União, cabe “assegurar processo nacional de avaliação do rendimento escolar no ensino fundamental, 
médio e superior, em colaboração com os sistemas de ensino, objetivando a definição de prioridades e a melhoria da qualidade do ensino".

Resgatando a história, podemos afirmar que, desde a Constituição Federal de 1988, constatamos um avanço no desenvolvimento e implementação de políticas de avaliação em larga escala para aferição da educação nacional. Neste contexto, a avaliação em larga escala foi implementada pelo Ministério da Educação (MEC), com o objetivo de possibilitar uma percepção mais ampla da realidade e contribuir para diagnosticar a situação da educação brasileira, visando sua melhoria quantitativa e qualitativa.

No ano de 1990, foi aplicado pela primeira vez o Sistema Nacional de Avaliação da Educação Básica (SAEB), por meio do Instituto Nacional de Estudos e Pesquisas Educacionais Anísio Teixeira (INEP). É aplicado de dois em dois anos, avaliou alunos de $4^{\mathrm{a}} \mathrm{e}$ $8^{\mathrm{a}}$ séries do ensino fundamental e do $3^{\circ}$ ano do ensino médio, da rede pública e da rede privada, de escolas localizadas nas áreas urbana e rural. Os alunos fazem prova de Língua Portuguesa (foco na leitura) e Matemática (foco na resolução de problemas).

Em 2005, objetivando a obtenção de dados mais detalhados sobre a realidade educacional, foi elaborada a Prova Brasil, que tem como objetivo avaliar censitariamente, em Língua Portuguesa e Matemática, alunos da $4^{\mathrm{a}}$ série e $8^{\mathrm{a}}$ séries do Ensino Fundamental ou $5^{\circ} \mathrm{e}$ $9^{\circ}$ anos de escolaridade, contemplando as redes de ensino que ampliaram o ensino Fundamental para 9 anos.

Em 2007, o Ministro de Estado da Educação Fernando Haddad, no uso de suas atribuições, por meio da Portaria Normativa Nº 10, de 24 de abril de 2007, resolve:

Art. $1^{\circ}$ Fica instituída a Avaliação de Alfabetização "Provinha Brasil", a ser estruturada pelo Instituto Nacional de Estudos e Pesquisas Educacionais "Anísio Teixeira" - INEP [...]. Art. $2^{\circ}$ A Avaliação de Alfabetização "Provinha Brasil" tem por objetivo: a) avaliar o nível de alfabetização dos educandos nos anos iniciais do ensino fundamental; b) oferecer às redes de ensino um resultado da qualidade do ensino, prevenindo o diagnostico tardio das dificuldades de aprendizagem; e c) concorrer para a melhoria da qualidade de ensino e redução das desigualdades, em consonância com as metas e políticas estabelecidas pelas diretrizes da educação nacional [...].

A partir da referida Portaria, ao longo de 2007, em função de demandas cada vez mais crescentes, em relação à avaliação do processo de alfabetização, nos anos iniciais do Ensino Fundamental, o INEP elaborou a Provinha Brasil, a qual foi aplica pela primeira vez em 2008, e sistematicamente vem sendo aplicada anualmente em dois períodos, no início e ao término 
do ano letivo. Essa metodologia de avaliação, segundo o INEP, no documento "Passo a Passo", tem em vista "auxiliar o monitoramento e a avaliação dos processos e resultados da alfabetização oferecida nas escolas públicas brasileiras".

O instrumental da Provinha Brasil se constitui em um kit composto por sete documentos: Passo a Passo, Orientações para as Secretarias de Educação, Caderno de Teste do Aluno, Caderno do Professor/Aplicador I: Orientações Gerais, Caderno do Professor/Aplicador II: Guia de Aplicação, Guia de Correção e Interpretação dos Resultados, e Reflexões sobre a Prática.

Em nossa investigação, tomamos para analise o kit da Provinha Brasil ${ }^{3}$ do primeiro e do segundo semestre do ano de 2009, com exceção, do "Caderno do Aluno" e "Guia de Aplicação" do primeiro semestre de 2010. Discorremos, a seguir, algumas considerações sobre os documentos que constitui o instrumental da Provinha Brasil:

O documento Passo a Passo, oferece informações referentes ao contexto de criação e implementação da Provinha Brasil, seus objetivos, apresentam os pressupostos teóricos que a fundamentam, suas metodologias, e ainda, as possibilidades de interpretação e uso dos seus resultados, bem como as perspectivas para os próximos ciclos.

Nesse documento se faz menção aos indicadores produzidos desde 1990, resultantes das aplicações do SAEB, apontando déficits no ensino oferecido pelas escolas brasileiras. De acordo com o documento supracitado, diante dessa realidade, para reverter esse quadro, uma das iniciativas diz respeito à ampliação do ensino fundamental de oito para nove anos de estudo. Tornou-se meta da educação nacional pela Lei $n^{\circ} 10.172 / 2001$, visando assegurar a todas as crianças "um tempo mais longo de convívio escolar e, conseqüentemente, maiores oportunidades de aprendizagem". ${ }^{4}$

Outra medida adotada pelo MEC foi o lançamento do Plano de Desenvolvimento da Educação (PDE), o qual é constituído por quarenta e três programas, entre eles, destacamos a

\footnotetext{
${ }^{3}$ O qual foi elaborado pelo Instituto Nacional de Estudos e Pesquisas Educacionais Anísio Teixeira (INEP), pela Diretoria de Avaliação da Educação Básica (DAEB), e pela Coordenação Geral do Sistema Nacional de Avaliação da Educação Básica. Com a colaboração das seguintes Instituições: Ministério da Educação e Cultura (MEC), Secretaria de Educação Básica (SEB/MEC), Centro de Alfabetização Leitura e Escrita da Universidade Federal de Minas Gerais (CEALE), Centro de Formação Continuada de Professores da Universidade de Brasília (CEFORM), Centro de Formação Continuada, Desenvolvimento de Tecnologias e Prestação de Serviços para as Redes Públicas de Ensino da Universidade Federal de Ponta Grossa (CEFORMTEC), Centro de Estudos em Educação e Linguagem da Universidade Federal de Pernambuco (CEEL), e Centro de Políticas Públicas e Avaliação da Educação da Universidade Federal de Juiz de Fora (CAED). Sob a consultoria de Hilda Aparecida Linhares da Silva Micarello e Vera Masagão Ribeiro.
}

${ }^{4}$ Cf. BRASIL/MINISTÉRIO DA EDUCAÇÃO/SEB. Ensino fundamental de nove anos: Orientações para a inclusão da criança de seis anos de idade. Brasília: FNDE, 2006, p.135. 
Provinha Brasil, que foi instituída na perspectiva de melhorar os níveis de letramento, visto que o SAEB não investiga as habilidades relacionadas ao processo de alfabetização. ${ }^{5}$

Os resultados da Provinha Brasil não são utilizados para a composição do Índice de Desenvolvimento da Educação Básica (IDEB). A Provinha Brasil foi preparada para ser aplicada às crianças que estão matriculadas no segundo ano de escolarização de cada unidade de ensino. Conforme está explicitado no artigo $2^{\circ}$, inciso II, do Plano de Metas Compromisso Todos Pela Educação, que expressa a necessidade de "alfabetizar as crianças até, no máximo, os oito anos de idade, aferindo os resultados por meio de exame periódico específico".

Por meio da Provinha Brasil são avaliadas habilidades relativas à alfabetização e ao letramento inicial dos estudantes. O método de alfabetização adotado nas questões do caderno do aluno da Provinha Brasil consiste no método analítico. Segundo Larocca; Saveli (2001, p. 188), no método analítico “[...] a criança deverá partir de estruturas completas, consideradas mais significativas, para chegar, a posteriori, à discriminação das partes menores".

Neste método as atividades são elaboradas a partir da palavra, da frase ou do texto. Para ilustrar a presença do método analítico na Provinha Brasil, citamos duas questões do caderno do aluno do $1^{\mathrm{o}}$ semestre de 2009:

Na questão 1: há um desenho de uma mala com quatro alternativas: FALA, MALA, BALA, SALA. No "Caderno do Professor/Aplicador - II" (Guia de aplicação) há a seguinte instrução: "leia para os alunos SOMENTE a INSTRUÇÃO em que aparece o megafone. Repita a leitura, no máximo, duas vezes". O professor/aplicador lê: "Faça um X no quadrinho onde está escrito MALA".

Na questão 15: instrução para o professor/aplicador é a seguinte: “[...] para se referir à palavra "sílaba" utilize o nome que seus alunos estão habituados (sílaba, parte, pedacinho, etc.)". Em seguida o professor/aplicador faz aos alunos duas instruções: "Veja o desenho silenciosamente", que é de uma borboleta. Após os alunos observarem, ele diz: "Faça um X no quadrinho onde está escrita a última sílaba do nome do desenho que você viu". As alternativas são: a) BOR; b) LE; c) BO; d) TA.

A Provinha Brasil foi implantada no Brasil no intuito de diagnosticar a realidade do processo de alfabetização e letramento no cenário educacional brasileiro, e assim melhorar a qualidade do ensino. Ressaltamos que o instrumental da Provinha Brasil é uniforme para todo o território nacional, suas questões são objetivas e de múltipla escolha.

\footnotetext{
${ }^{5}$ O SAEB avalia apenas as habilidades das disciplinas de Língua Portuguesa e Matemática de determinados ciclos de ensino, ou seja, $4^{\mathrm{a}}$ e $8^{\mathrm{a}}$ séries $\left(5^{\circ}\right.$ e $9^{\circ}$ anos) do ensino fundamental e $3^{\mathrm{a}}$ série do ensino médio.
} 
Perguntamos a uma das coordenadoras da Secretaria Municipal de Educação do Município de Irati, a respeito do material utilizado para a aplicação da Provinha Brasil, ela expõe:

Um bom material ele é, mas necessitaria de mais explanações a respeito do que realmente é a proposta, porque ele ainda se baseia na questão de níveis da escrita, considerando o principio, a base da alfabetização, [...] ele verifica a questão de nível de escrita, ou seja, se a criança adquiriu o sistema alfabético, no caso. Eles procuram contextualizar, mas ainda existem alguns pontos, que na minha opinião, eu considero que deveriam ser revistos. Visa mais a alfabetização e não o letramento, até é pedido algumas interpretações, mas ela não dá oportunidade de a criança expressar na escrita, até porque são questões objetivas, ele é um instrumento de medida, então é mensurável, então eles fazem questões objetivas para que tenha uma correção padrão. Ele é o mesmo material para todo território nacional, então ele não é especifico para a região, ele é um meio. [...] Ele não é de todo ruim porque ele dá uma base para as escolas, os diretores e professores, para verem se realmente a criança está compreendendo, principalmente se a criança sabe diferenciar símbolos de letras, de números, se conseguem interpretar textos pequenos, mas ao mesmo tempo acaba nivelando [...].

A afirmação da coordenadora, de que a Provinha Brasil visa mais à alfabetização e não o letramento, aqui abrimos foco, uma vez que alfabetização e letramento são indissociáveis, cada um desses conceitos tem sua especificidade, no entanto, o processo ocorre de forma conjunta. Alfabetização consiste na codificação e decodificação de signos, enquanto, o letramento consiste na interpretação e compreensão da leitura e da escrita, em outras palavras, é quando aluno consegue utilizar aquilo que apreendeu da leitura e da escrita em sua prática social.

Para Soares (1998, p. 39), o letramento é "o resultado da ação de ensinar e aprender as práticas sociais de leitura e escrita; o estado ou condição que adquire um grupo social ou um indivíduo como conseqüência de ter-se apropriado da escrita e de suas práticas sociais”.

Refletindo a esse respeito, também percebemos a contradição presente nas políticas educacionais brasileira, uma vez que este tipo de avaliação não considera a autonomia da instituição escolar, propagada na LDB 9394/96, a qual salienta que a autonomia se concretiza na elaboração do Projeto Político Pedagógico, assim cada escola tem o direito por lei de adotar uma concepção pedagógica que melhor responda a sua demanda. Pois, o material que vem do MEC está fundamentado nos Parâmetros Curriculares Nacionais para a Educação, que tem como linha pedagógica o construtivismo. Neste sentido, constatamos que por esse motivo nem sempre a avaliação em larga escala se torna um instrumento eficaz para ilustrar a 
realidade da educação brasileira. No próximo item analisamos a aplicação da Provinha Brasil no contexto do município de Irati.

\section{A PROVINHA BRASIL NO CONTEXTO IRATIENSE}

No município de Irati, a Provinha Brasil começou a ser aplicada em 2008. Para conhecer o processo de efetivação da Provinha Brasil no contexto iratiense, neste item, utilizamos dados quantitativos e qualitativos.

Para compreender melhor o processo de aplicação da Provinha Brasil no município de Irati, entrevistamos uma das coordenadoras da Secretaria Municipal de Educação, que faz a seguinte explanação:

A primeira aplicação que teve da Provinha Brasil, antes de a gente levar para as escolas, foi feito um estudo do material que chegou até a Secretaria, e depois de feita a leitura dos manuais, que vem os livros de instruções, vem o material para a Secretaria. A gente procurou entender qual era o objetivo, qual a necessidade, o porquê dessa avaliação já nos primeiros anos e aí foi realizada uma reunião com os diretores e coordenadores das escolas. No ano de 2008, todas as escolas municipais participaram [...]

No ano de 2008, a Provinha Brasil aconteceu no dia 30 de maio em todas as escolas municipais e foi aplicada aos alunos da $2^{\text {a }}$ série do Ensino Fundamental de 8 anos. Os resultados obtidos na avaliação alcançaram um índice de aproveitamento no município de $88,2 \%$. No entanto, lembramos que nem todas as escolas alcançaram esse índice, como podemos observar nos dados abaixo, a porcentagem de acertos nas questões objetivas ficou entre $76,7 \%$ a $97,2 \%$, e nas questões de escrita a média de acertos entre as escolas ficou entre $71,4 \%$ a $100 \%$.

Por isso, nem sempre a média geral do município será coerente com os resultados de cada escola. Pois, cada escola é peculiar, seus resultados são diferentes, e assim as escolas que se saíram com melhores resultados acabam maquiando os resultados não tão bons de outras escolas.

Tabela 1: Resultados obtidos de cada escola na aplicação da Provinha Brasil em 2008.

\begin{tabular}{|c|c|c|c|}
\hline $\begin{array}{c}\text { ESCOLAS MUNICIPAIS DE } \\
\text { IRATI }\end{array}$ & $\begin{array}{c}\mathbf{N}^{\circ} \text { DE } \\
\text { ALUNOS QUE } \\
\text { FORAM }\end{array}$ & $\begin{array}{c}\text { PORCENT. } \\
\text { ACERTOS } \\
\text { (OBJETIVAS) }\end{array}$ & $\begin{array}{c}\text { PORCENT. } \\
\text { ACERTOS } \\
\text { (ESCRITA) }\end{array}$ \\
\hline
\end{tabular}




\begin{tabular}{|l|l|l|l|}
\hline & AVALIADOS & & \\
\hline ESCOLA 1 & 16 & 89,8 & 95,8 \\
\hline ESCOLA 2 & 23 & 88,9 & 89,8 \\
\hline ESCOLA 3 & 20 & 94,7 & 80 \\
\hline ESCOLA 4 & 09 & 97,2 & 85,1 \\
\hline ESCOLA 5 & 39 & 79,4 & 80,3 \\
\hline ESCOLA 6 & 46 & 90,4 & 94,9 \\
\hline ESCOLA 7 & 67 & 85 & 74 \\
\hline ESCOLA 8 & 35 & 82,2 & 86,8 \\
\hline ESCOLA 9 & 86 & 95 & 98,3 \\
\hline ESCOLA 10 & 30 & 90,2 & 90 \\
\hline ESCOLA 11 & 50 & 89,3 & 88 \\
\hline ESCOLA 12 & 21 & 90,8 & 88,8 \\
\hline ESCOLA 13 & 25 & 85 & 81,3 \\
\hline ESCOLA 14 & 07 & 76,7 & 71,4 \\
\hline ESCOLA 15 & 08 & 82,8 & 83,3 \\
\hline ESCOLA 16 & 10 & 82 & 80 \\
\hline ESCOLA 17 & 48 & 84,8 & 88,8 \\
\hline ESCOLA 18 & 09 & 88,8 & 100 \\
\hline ESCOLA 19 & 38 & 84,6 & 90,3 \\
\hline ESCOLA 20 & 12 & 88,5 & 91,6 \\
\hline ESCOLA 21 & 46 & 79,6 & 69,5 \\
\hline ESCOLA 22 & 67 & 89,1 & 85 \\
\hline ESCOLA 23 & 28 & 93,7 & 96,4 \\
\hline ESCOLA 24 & 26 & 85,5 & 87,1 \\
\hline ESCOLA 25 & 15 & 89,1 & 97,7 \\
\hline ESCOLA 26 & 30 & 89,6 & 91,1 \\
\hline ESCOLA 27 & 96 & 87 & 79,8 \\
\hline ESCOLA 28 & 23 & 92,6 & 86,9 \\
\hline ESCOLA 29 & 33 & 86,2 & 84,8 \\
\hline ESCOLA 30 & 37 & 86,4 & 78,5 \\
\hline ESCOLA 40 & 34 & 91,7 & 93 \\
\hline E 109 & \\
\hline
\end{tabular}

Fonte: Dados fornecidos pela Secretaria Municipal de Educação de Irati, 2010.

Tabela 2: Acertos das questões dos alunos da $2^{\mathrm{a}}$ série na Provinha Brasil - 2008

\begin{tabular}{|l|r|}
\hline Questão 1 & $98,9 \%$ \\
\hline Questão 2 & $95,5 \%$ \\
\hline Questão 3 & $97,1 \%$ \\
\hline Questão 4 & $97,1 \%$ \\
\hline Questão 5 & $96,5 \%$ \\
\hline Questão 6 & $90 \%$ \\
\hline Questão 7 & $96 \%$ \\
\hline Questão 8 & $96,2 \%$ \\
\hline Questão 9 & $87,8 \%$ \\
\hline Questão 10 & $89,2 \%$ \\
\hline Questão 11 & $90,3 \%$ \\
\hline Questão 12 & $92,1 \%$ \\
\hline
\end{tabular}




\begin{tabular}{|l|r|}
\hline Questão 13 & $88,2 \%$ \\
\hline Questão 14 & $87,7 \%$ \\
\hline Questão 15 & $89,4 \%$ \\
\hline Questão 16 & $76,7 \%$ \\
\hline Questão 17 & $90,1 \%$ \\
\hline Questão 18 & $82,6 \%$ \\
\hline Questão 19 & $77,1 \%$ \\
\hline Questão 20 & $85,7 \%$ \\
\hline Questão 21 & $84 \%$ \\
\hline Questão 22 & $74,1 \%$ \\
\hline Questão 23 & $69 \%$ \\
\hline Questão 24 & $71,8 \%$ \\
\hline Escrita & 88,2 \\
\hline
\end{tabular}

Fonte: Dados fornecidos pela Secretaria Municipal de Educação de Irati, 2010.

A Coordenadora da referida Secretaria sobre os resultados apresentados considera que:

Com base nos resultados foi realizada uma reunião com os diretores $e$ coordenadores, na qual a equipe pedagógica da Secretaria Municipal apresentou os resultados contendo os indicadores favoráveis e os que precisam ser revistos no processo de processo de alfabetização [...].

E complementa, ressaltando:

[...] que a Provinha Brasil é um dos instrumentos utilizados para que as secretarias e escolas possam trabalhar com as informações produzidas que servem de base para orientar as ações pedagógicas $e$ o desenvolvimento de políticas que poderão, em conjunto, mudar os índices de desempenho quando se apresentarem insatisfatórios.

Aqui, fica uma questão: será que este instrumento está sendo utilizado para pelas escolas como orientação das ações pedagógicas?

Em 2009, vinte e nove escolas municipais de Irati aplicaram a Provinha Brasil, alcançando os seguintes índices: no teste 1: $87 \%$ de acertos e 13\% de questões erradas; no teste 2: $91 \%$ de acertos e $9 \%$ de erros. Esses números são relativos às 24 questões objetivas do primeiro semestre, bem como do segundo semestre. Uma vez que a partir desse ano não foi mais avaliada a escrita na Provinha Brasil.

A aplicação da Provinha Brasil no primeiro semestre de 2010 no município de Irati, ilustramos com os dados abaixo: 
Tabela 3: Resultado detalhado de todas as escolas municipais na aplicação da Provinha Brasil Teste 1 - 2010

\begin{tabular}{|c|c|c|c|c|c|c|c|c|c|c|}
\hline \multirow{2}{*}{ QUESTÃO } & \multicolumn{2}{|c|}{ C } & \multicolumn{2}{|c|}{$\mathbf{E}$} & \multicolumn{2}{|c|}{ Inválida } & \multicolumn{2}{|c|}{ Em branco } & \multicolumn{2}{|c|}{ Total } \\
\hline & $\mathbf{N}^{\mathbf{0}}$ & $\%$ & $\mathrm{~N}^{\mathbf{0}}$ & $\%$ & $\mathbf{N}^{\mathbf{o}}$ & $\%$ & $\mathbf{N}^{\mathbf{0}}$ & $\%$ & $\mathbf{N}^{\mathbf{0}}$ & $\%$ \\
\hline 1 & 767 & 99,0 & 7 & 0,9 & 1 & 0,1 & 0 & 0,0 & 775 & 100 \\
\hline 2 & 765 & 98,7 & 8 & 1,0 & 2 & 0,3 & 0 & 0,0 & 775 & 100 \\
\hline 3 & 765 & 98,7 & 10 & 1,3 & 0 & 0,0 & 0 & 0,0 & 775 & 100 \\
\hline 4 & 769 & 99,2 & 6 & 0,8 & 0 & 0,0 & 0 & 0,0 & 775 & 100 \\
\hline 5 & 764 & 98,6 & 7 & 0,9 & 4 & 0,5 & 0 & 0,0 & 775 & 100 \\
\hline 6 & 770 & 99,4 & 4 & 0,5 & 1 & 0,1 & 0 & 0,0 & 775 & 100 \\
\hline 7 & 762 & 98,3 & 11 & 1,4 & 1 & 0,1 & 1 & 0,1 & 775 & 100 \\
\hline 8 & 754 & 97,3 & 19 & 2,5 & 0 & 0,0 & 2 & 0,3 & 775 & 100 \\
\hline 9 & 765 & 98,7 & 10 & 1,3 & 0 & 0,0 & 0 & 0,0 & 775 & 100 \\
\hline 10 & 723 & 93,3 & 49 & 6,3 & 2 & 0,3 & 1 & 0,1 & 775 & 100 \\
\hline 11 & 747 & 96,4 & 26 & 3,4 & 2 & 0,3 & 0 & 0,0 & 775 & 100 \\
\hline 12 & 745 & 96,1 & 29 & 3,7 & 0 & 0,0 & 1 & 0,1 & 775 & 100 \\
\hline 13 & 741 & 95,6 & 33 & 4,3 & 1 & 0,1 & 0 & 0,0 & 775 & 100 \\
\hline 14 & 746 & 96,3 & 29 & 3,7 & 0 & 0,0 & 0 & 0,0 & 775 & 100 \\
\hline 15 & 700 & 90,3 & 71 & 9,2 & 4 & 0,5 & 0 & 0,0 & 775 & 100 \\
\hline 16 & 695 & 89,7 & 78 & 10,1 & 2 & 0,3 & 0 & 0,0 & 775 & 100 \\
\hline 17 & 695 & 89,7 & 79 & 10,2 & 1 & 0,1 & 0 & 0,0 & 775 & 100 \\
\hline 18 & 688 & 88,8 & 86 & 11,1 & 1 & 0,1 & 0 & 0,0 & 775 & 100 \\
\hline 19 & 662 & 85,4 & 111 & 14,3 & 2 & 0,3 & 0 & 0,0 & 775 & 100 \\
\hline 20 & 640 & 82,6 & 130 & 16,8 & 4 & 0,5 & 1 & 0,1 & 775 & 100 \\
\hline 21 & 700 & 90,3 & 72 & 9,3 & 3 & 0,4 & 0 & 0,0 & 775 & 100 \\
\hline 22 & 667 & 86,1 & 105 & 13,5 & 3 & 0,4 & 0 & 0,0 & 775 & 100 \\
\hline 23 & 660 & 85,2 & 115 & 14,8 & 0 & 0,0 & 0 & 0,0 & 775 & 100 \\
\hline 24 & 557 & 71,9 & 214 & 27,6 & 3 & 0,4 & 1 & 0,1 & 775 & 100 \\
\hline
\end{tabular}

Fonte: Secretaria Municipal de Educação de Irati, 2010.

Tabela 4: Resultado de cada escola municipal de Irati na aplicação da Provinha Brasil Teste 1 -2010 .

\begin{tabular}{|l|r|r|}
\hline & & \\
ESCOLAS & ACERTOS DO TESTE 1 & ERROS DO TESTE 1 \\
\hline ESCOLA 1 & $97 \%$ & $3 \%$ \\
\hline ESCOLA 2 & $95 \%$ & $5 \%$ \\
\hline ESCOLA 3 & $100 \%$ & $0 \%$ \\
\hline ESCOLA 4 & $96 \%$ & $4 \%$ \\
\hline ESCOLA 5 & $98 \%$ & $2 \%$ \\
\hline ESCOLA 6 & $98 \%$ & $2 \%$ \\
\hline ESCOLA 7 & $90 \%$ & $10 \%$ \\
\hline ESCOLA 8 & $90 \%$ & $10 \%$ \\
\hline ESCOLA 9 & $96 \%$ & $4 \%$ \\
\hline ESCOLA 10 & $95 \%$ & $5 \%$ \\
\hline ESCOLA 11 & $99 \%$ & $1 \%$ \\
\hline
\end{tabular}




\begin{tabular}{|l|r|r|}
\hline ESCOLA 12 & $90 \%$ & $10 \%$ \\
\hline ESCOLA 13 & $93 \%$ & $7 \%$ \\
\hline ESCOLA 14 & $83 \%$ & $17 \%$ \\
\hline ESCOLA 15 & $79 \%$ & $21 \%$ \\
\hline ESCOLA 16 & $99 \%$ & $1 \%$ \\
\hline ESCOLA 17 & $92 \%$ & $8 \%$ \\
\hline ESCOLA 18 & $93 \%$ & $7 \%$ \\
\hline ESCOLA 19 & $98 \%$ & $2 \%$ \\
\hline ESCOLA 20 & $94 \%$ & $6 \%$ \\
\hline ESCOLA 21 & $94 \%$ & $6 \%$ \\
\hline ESCOLA 22 & $88 \%$ & $12 \%$ \\
\hline ESCOLA 23 & $91 \%$ & $9 \%$ \\
\hline ESCOLA 24 & $90 \%$ & $10 \%$ \\
\hline ESCOLA 25 & $92 \%$ & $8 \%$ \\
\hline ESCOLA 26 & $91 \%$ & $9 \%$ \\
\hline ESCOLA 27 & $96 \%$ & $4 \%$ \\
\hline ESCOLA 28 & $85 \%$ & $15 \%$ \\
\hline ESCOLA 29 & $96 \%$ & $4 \%$ \\
\hline EO
\end{tabular}

Fonte: Secretaria Municipal de Educação de Irati, 2010.

O município alcançou um total geral de $93 \%$ de acertos e $7 \%$ de erros. Conforme demonstra o gráfico:

Gráfico 1: Acertos e erros: Teste 1.

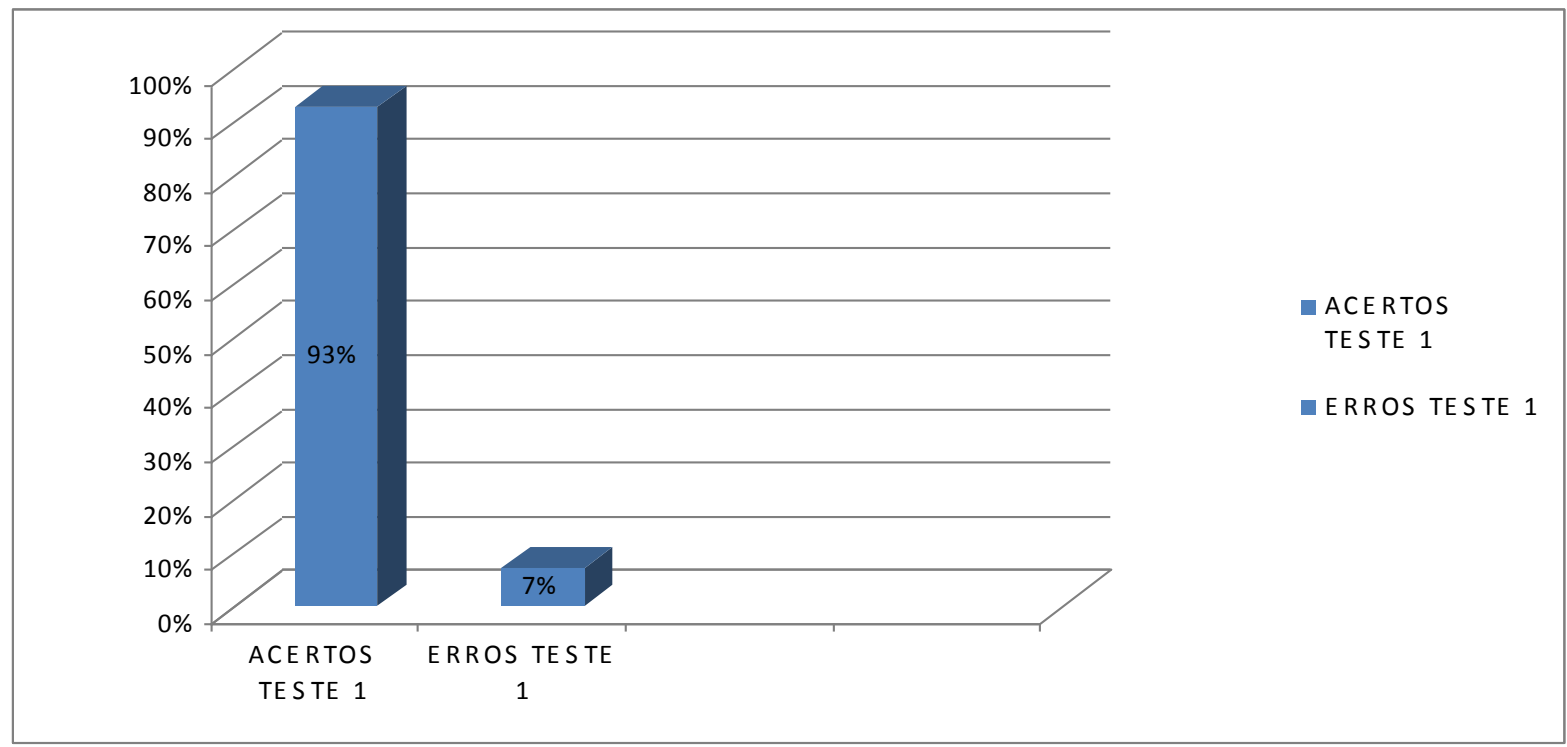

Fonte: Secretaria Municipal de Educação de Irati, 2010. 
A partir desses dados fica evidente que o município de Irati, a cada ano está aumentando os seus índices. Mas, sabemos que os resultados nem sempre condizem com a realidade de cada escola, com a aprendizagem concreta dos alunos Por diversos fatores, eles os quais destacamos: a) a Provinha Brasil, pode ser aplicada pelo próprio professor da turma, podendo este interferir diretamente ou indiretamente nos resultados; b) a escola pode alterar os resultados devido à cobrança da entidade mantenedora, e até mesmo por competição entre as escolas; c) $\mathrm{O}$ aluno pode assinalar a resposta aleatoriamente, e acaba acertando, assim não condizendo com sua capacidade de compreensão da leitura e da escrita.

Nessa linha de pensamento, a coordenadora entrevistada aponta que:

[...] quem aplica a prova é o professor, então, a gente não sabe se realmente esse professor deixou o aluno ler, ou não foi lido pelo professor, ou ainda, a questão do aluno marcar a questão e acertar. Então, neste ponto teria que fazer uma investigação mais profunda, minuciosamente, escola por escola, sala por sala.

Ressaltamos que estas hipóteses levantadas no que refere aos fatores que podem interferir nos resultados da aplicação da Provinha Brasil, para comprovar teria que se realizar uma investigação mais minuciosa a esse respeito.

Em relação aos resultados obtidos no município de Irati, a coordenadora entrevistada acentua:

No município de Irati, no todo [...] ele teve resultado satisfatório, isso dentro da avaliação. [...] $O$ instrumento te dão a base, mas se a Secretaria e as escolas não trabalharem firme, não fizerem os questionamentos e não trabalharem os professores, para ver os fatores que interfere, ele não vai mudar por si os resultados da escrita e da leitura. Os objetivos do MEC foram contemplados, tanto que a gente tem que tabular gráficos, apresentar gráficos. O município tem que demonstrar que está acima de $70 \%$ [...]

Outro gráfico que merece destaque consiste nos dados relativos a cada questão da Provinha Brasil - Teste 1 de 2010. Conforme ilustramos:

Gráfico 2:

\section{Acertos das questões dos alunos da $2^{a}$ série na Provinha Brasil Teste 1 - 2010}

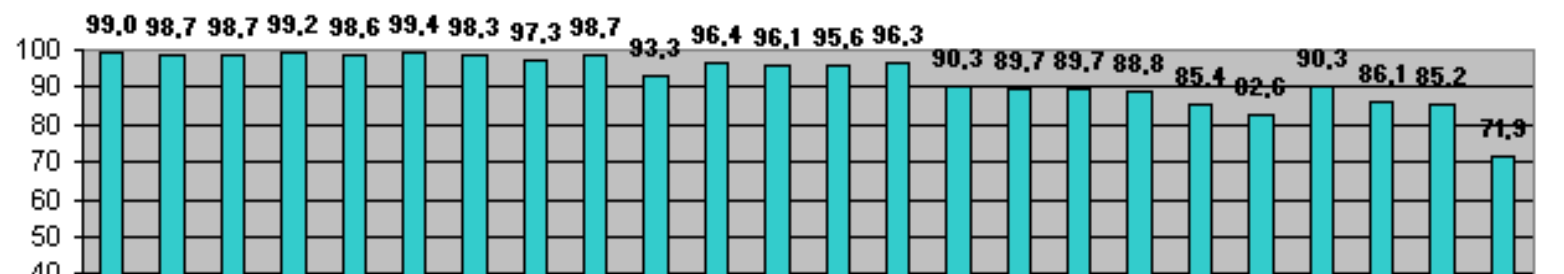


Fonte: Secretaria Municipal de Educação de Irati, 2010.

Como podemos constatar no gráfico, as primeiras questões da Provinha Brasil tem um índice até de 99, 4\% de acertos no total geral das escolas municipais. No entanto, nas últimas questões o índice diminui para até $71,9 \%$.

O que levou a essa queda nos números? A resposta está na análise de cada questão, realizada no segundo item, pois as questões relativas somente a alfabetização, com a ajuda do professor/aplicador os alunos tiveram mais facilidade de responder as questões. No que se refere às questões de letramento, ou seja, de interpretação e compreensão do texto, os alunos tiveram maiores dificuldades.

Di Nucci (2001) aponta que devemos entender o processo de alfabetização sob uma perspectiva de letramento, e coloca o desafio, para os educadores, de alfabetizar letrando.

No moldes de Di Nucci (2001 p. 69):

Para alfabetizar e letrar uma criança, o professor deve propor atividades que envolvam a leitura e a escrita na forma em que estas estão contextualizadas, ou seja, a partir das práticas cotidianas reais de escrita da criança. É preciso que ela perceba as funções da escrita e sinta-se inserida num contexto equivalente ao seu cotidiano extraescolar.

A partir dessa explanação, e observando os dados da aplicação da Provinha Brasil no município de Irati, constatamos que o desafio continua é preciso alfabetizar letrando. Mas, ressaltamos que não podemos relativizar esses resultados, uma vez que essa natureza de avaliação acaba não sendo coerente à Proposta Curricular do município de Irati, que tem como linha pedagógica a perspectiva da Pedagogia Histórico Crítica ${ }^{6}$.

\footnotetext{
${ }^{6}$ Nessa formulação a educação é entendida como mediação no seio da prática social global. A prática social se põe, portanto, como o ponto de partida e o ponto de chegada da prática educativa. Daí decorre um método pedagógico que parte da prática social onde professor e aluno se encontram igualmente inseridos ocupando, porém, posições distintas, condição para que travem uma relação fecunda na compreensão e encaminhamento da solução dos problemas postos pela prática social, cabendo aos momentos intermediários do método identificar as questões suscitadas pela prática social (problematização),
} 
Sendo assim, uma das coordenadoras da educação municipal de Irati em relação a essa problemática, faz a seguinte consideração:

Em partes, algumas questões dá para se considerar que estão dentro da Proposta Curricular do município, mas outras permanecem bem descontextualizadas. Ele tem um misto. Mas, em contrapartida, o município não fica só com a avaliação da Provinha Brasil. Desde 2009 foi adotado um sistema de avaliação do município, que é aplicado para todas as séries, desde o $1^{o}$ ano, $1^{a}$ série até a $4^{a}$ série, aonde daí são vistos os resultados e analisados o que realmente os alunos sabem ler, as potencialidades. Até por uma opinião minha mesmo, nunca se deve basear só em um instrumento de avaliação. Mesmo porque a Provinha Brasil tem uma data certa, neste dia podem acontecer inúmeros fatores que podem interferir nesses resultados [...].

A partir desses apontamentos, percebemos que a Provinha Brasil acaba nivelando justamente por ser uniforme para todo território brasileiro, não considerando as peculiaridades de cada sistema de ensino, bem como de cada escola. No próximo item, apresentamos algumas considerações em relação ao estudo acima.

\section{REFLEXÕES SOBRE OS DADOS LEVANTADOS}

Alguns apontamentos...

Com a instauração da ideologia neoliberal no Brasil, principalmente na década de 1990, as políticas educacionais brasileiras passaram a ser desenhadas conforme a ótica do capital sob a égide do neoliberalismo. Os neoliberais não se intimidam em afirmar de quem deve organizar o Estado é o mercado/capital. Portanto, o Estado é mínimo, e quando o capitalismo entra em crise, se corta tudo o que está relacionado ao social, se foca exclusivamente na salvação desse sistema.

Assim, o Estado se torna mais fraco que o capital e as agências internacionais. No entanto, sob o interesse do capital, o Estado aparente-se forte nas determinações das políticas públicas internamente, mas extremamente fraco diante dos organismos externos.

Segundo Sanfelice (2010) ${ }^{7}$, a partir da expansão do movimento neoliberal, juntamente com a globalização no Brasil, as políticas educacionais nacionais passaram a ser focadas na

\footnotetext{
dispor os instrumentos teóricos e práticos para a sua compreensão e solução (instrumentalização) e viabilizar sua incorporação como elementos integrantes da própria vida dos alunos (catarse) (SAVIANI, 2005, p. 26)

7 Palestra "Educação, Conhecimento e o Mundo Globalizado", ministrada por José Luis Sanfelice, no II Congresso Internacional de Educação, Ponta Grossa - Paraná - Brasil, 27 a 29 de Maio de 2010.
} 
ótica do mercado: utilitarista, competitiva e individualista. Na sua fala, o palestrante salienta ainda que desde 1990, as políticas educacionais brasileiras não têm uma vírgula que não esteja ligada com o Banco Mundial. Entre as reformas educacionais, o palestrante destaca: LDB 9394 de 1996, PCNs, introdução dos temas transversais, empresariamento dos livros didáticos, avaliação em larga escala, e a municipalização.

Nesta linha de pensamento, para compreender melhor a realidade da educação no Brasil, extrapolamos um pouco a década de 1990, e percebemos quão grande a contradição presente no cenário educacional brasileiro.

A Constituição Federal de 1988, no Art. 206, Inciso VI, define a "gestão democrática do ensino público, na forma da lei” como um dos seus princípios. No mesmo sentido também a LDB 9394 de 1996, no Art. 14, Incisos I e II, se expressa:

Os sistemas de ensino definirão as normas da gestão democrática do ensino público na educação básica, de acordo com as suas peculiaridades e conforme os seguintes princípios: I - participação dos profissionais da educação na elaboração do projeto pedagógico da escola; II - participação das comunidades escolar e local em conselhos escolares ou equivalentes.

Como vemos, a LDB remete a regulamentação da gestão democrática do "ensino público na educação básica" aos sistemas de ensino, segundo Vieira (2009, p. 46):

[...] oferecendo ampla autonomia às unidades federadas para definirem, em sintonia com suas especificidades, formas de operacionalização de tal processo, o qual deve considerar o envolvimento dos profissionais de educação e as comunidades escolar e local. Em ambos os casos, a participação refere-se ao âmbito da escola: a elaboração de seu projeto pedagógico e a atuação em conselhos escolares ou equivalentes.

Ao discutirmos sobre o princípio de gestão democrática no ensino público, defendido por lei, também se tornou oportuno nesta investigação trazer em pauta o discurso de autonomia tão propagado desde a década de 1990 até os dias atuais, nas reformas educacionais brasileiras.

A autonomia das unidades escolares é decreta nos dispositivos da LBD 9394/96, no Art. 15, da seguinte forma: “Os sistemas de ensino assegurarão às unidades escolares públicas de educação básica que os integram progressivos graus de autonomia pedagógica e administrativa e de gestão financeira, observadas as normas gerais de direito financeiro 
público". A referida LDB, no Art. 3, Inciso III, defende “o pluralismo das idéias e de concepções pedagógicas". No Art. 12, Inciso I, decreta que os estabelecimentos de ensino têm a incumbência de elaborar e executar sua proposta pedagógica.

Neste sentido, realizamos a seguinte reflexão: num país, que propaga os princípios de gestão democrática e autonomia. Como podemos conceber, então, neste mesmo país conviver com a avaliação em larga escala?

A partir dos estudos realizados no que se refere a esse tipo de avaliação, com ênfase na Provinha Brasil, ficou evidente a interferência dos organismos internacionais, sob a égide neoliberal, na elaboração da política de avaliação em larga escala no Brasil. Pois, sabemos que vivemos num sistema em que nunca se pensou de forma tão uniforme. De acordo com Sanfelice $(2010)^{8}$ sob a batuca dos organismos internacionais prolifera o capitalismo, e por meio dessas agências se constroem a ideologia.

Ideologia essa que se traduz na pedagogia hegemônica, que usa do discurso da inclusão, da equidade social, da qualidade do ensino. Por que não? Da gestão democrática, da autonomia dos estabelecimentos de ensino. Esses discursos são utilizados para conformar as pessoas. Muitas vezes somos alienados e pensamos: “eles pensam em mim”.

Relembrando concisamente os principais objetivos da "Provinha Brasil", que consiste na avaliação do nível de alfabetização nos anos iniciais do ensino fundamental; prevenir o diagnóstico tardio das dificuldades de aprendizagem; e concorrer para a melhoria da qualidade de ensino.

Certamente, ao depararmos diante desses objetivos, podemos concluir que realmente o governo está preocupado com a qualidade do ensino público. Mas, quando ultrapassamos nossa visão percebemos que a educação pública não é de interesse nosso, mas do Estado. Sanfelice (2010), diz: “a escola do Estado é financiado pelo povo, mas é do interesse do Estado".

Como todas as evidências apontam que o Brasil é um Estado extremamente subordinado aos organismos internacionais, especialmente ao Banco Mundial. Conseqüentemente, precisa constantemente prestar contas de suas ações no que se refere às políticas públicas por meio de números a essas agências externas.

Mas, qual a relação da Provinha Brasil com toda essa discussão? Os resultados dessa avaliação não são utilizados diretamente na composição do Índice de Desenvolvimento da

\footnotetext{
8 Palestra "Educação, Conhecimento e o Mundo Globalizado", ministrada por José Luis Sanfelice, no II Congresso Internacional de Educação, Ponta Grossa - Paraná - Brasil, 27 a 29 de Maio de 2010.
} 
Educação Básica (IDEB). Esse instrumento de avaliação visa orientar as ações políticas e pedagógicas que poderão melhorar o IDEB de estados e municípios a médio e longo prazo. No entanto, segundo a Coordenadora do município de Irati, "cada município tem que demonstrar que estão acima de 70\% de acertos na média geral”.

Neste sentido, torna-se possível afirmar que a Provinha Brasil é meio utilizado para melhorar o IDEB do Brasil, uma vez que objetiva precocemente identificar as dificuldades de aprendizagem, e posteriormente, essa melhoria dará resultado no índice de outras avaliações em larga escala.

Podemos dizer que a política de avaliação na educação brasileira tem como modelo o mercado, que por meio de números apresentados, classifica e gera competição. Na ótica de Arelaro (2003), as avaliações em larga escala geram competição, comparação e não solidariedade entre as escolas. Princípios defendidos pelo sistema capitalista sob o amparo da ideologia neoliberal. Neste sentido, fazemos a seguinte reflexão: qual pai ou qual mãe vai querer colocar seu filho em uma escola que apresenta baixos índices de aprendizagem?

Outro ponto de destaque que analisamos no instrumental da Provinha Brasil, é que essa natureza de avaliação é uniforme para todo território nacional, suas questões são objetivas e de múltipla escolha, utilizando-se do método de alfabetização analítico. Deixando um ponto de interrogação quando a contrapomos com os princípios de gestão democrática e autonomia. Pois, se cada estabelecimento de ensino tem incumbência de elaborar e executar sua proposta pedagógica; cada docente elabora seu próprio plano de trabalho pedagógico. Assim, salientamos que esse tipo de avaliação pode não ser coerente com a concepção pedagógica e metodologia de ensino de determina escola, e seus resultados podem não ser condizente com a realidade.

Para finalizar, no decorrer desta investigação constamos que nas duas últimas décadas, ocorreu o processo de descentralização da educação, especialmente da educação básica, nos primeiros anos que passaram a ser de responsabilidade dos municípios. Justificando-se pelo discurso de autonomia e gestão democrática.

Ao mesmo tempo, convivemos com um Estado centralizador, transformando-se no grande supervisor, que monitora e controla a educação brasileira por meio de resultados quantitativos.

\section{REFERÊNCIAS}


ARELARO, Lisete Regina Gomes. Direitos sociais e política educacional: alguns ainda são mais iguais que outros. In: SILVA, Shirley; VIZIM, Marli (orgs). Políticas públicas: educação, tecnologias e pessoas com deficiências. Campinas, São Paulo: Mercado de Letras: Associação de Leitura do Brasil, 2003.

BRASIL, Lei de Diretrizes e bases da Educação 9394/96.

BRASIL. Constituição República Federativa do Brasil 1988.

DI NUCCI, Eliane Porto. Alfabetizar letrando... Um desafio para o professor. In: DI NUCCI, Eliane Porto. Alfabetização e letramento. Campinas, São Paulo: Komedi, 2001.

GOMES NETO, João Batista; ROSENBERG, Lia. Indicadores de qualidade de ensino e seu papel no Sistema Nacional de Educação. Em aberto, v. 15, n. 66, pp. 13-28, jun., 1995. Acesso em: 10 de novembro de 2009.

SAVIANI, Demerval. As concepções pedagógicas na história da educação brasileira. Campinas: Histedbr, 2005 Disponível em: http//www.histedbr.fae.unicamp.br/navegando/artigos_frames/artigo_036.html. Acesso em 25/03/2010.

SOARES, Magda. Letramento: um tema em três gêneros. Belo Horizonte: Autentica, 1998.

VIEIRA, Sofia Lerche. Educação Básica: política e gestão da escola. Brasília: Liber Livro, 2009. 